\title{
Evaluating green suppliers: Improving supplier performance with DEA in the presence of incomplete data
}

\author{
Imre Dobos ${ }^{1}$, Gyöngyi Vörösmarty ${ }^{2}$ \\ ${ }^{1}$ Department of Economic Sciences, Budapest University of Technology and Economics \\ 1111 Bp. Magyar Tudósok körútja 2. Q ép. \\ dobos@kgt.bme.hu \\ ${ }^{2}$ Dept. of Logistics and Supply Chain Management, Corvinus University of Budapest \\ 1093 Budapest, Fővám tér 8., Hungary \\ gyongyi.vorosmarty@uni-corvinus.hu
}

Please cite this paper as:

Dobos, I., \& Vörösmarty, G. (2019). Evaluating green suppliers: improving supplier performance with DEA in the presence of incomplete data. Central European Journal of Operations Research, 27(2), 483-495.

\section{Introduction}

Suppliers are recognised as being key resources in an organisation. This makes supplier evaluation one of the most significant activities in purchasing and supply management (Kaufmann et al. 2010, Luzzini et al. 2014). The importance of this function is highlighted in the literature: the evaluation of suppliers provides information of use in strategic decisions related to supplier selection and supplier development, and plays a role in supply risk management. Reflecting on its importance to business, the role of purchasing is to create favourable conditions and successfully contract with suppliers who are able to fulfil requirements.

There has recently been a shift in the literature concerning how to obtain the right suppliers. Formerly, supplier selection and comparing bids were in focus, while the need for a more strategic approach has recently been emphasized. This approach highlights the need for complex evaluation processes and shifts attention to supplier management and supplier development in the creation of long-term competitive advantage and managing risk.

In this strategic context, purchasing relies on a broader toolset for evaluating suppliers, ensuring good performance and reducing the likelihood of non-performance. This multistage evaluation process involves undertaking a set of activities such as pre-qualification and post-qualification, alongside supplier selection, to ensure the availability of information about the performance and capabilities of suppliers. 
The literature has dealt in depth with the issue of supplier selection and many papers focus on how to compare offers, or experts opinion about the content of offers. However, relatively few publication have described how to support multi-stage evaluation. The development of such methodology faces new challenges, one of which is how to handle incomplete, missing or inaccurate information. This paper joins the discussion by addressing the methodological background in relation to the issue of handling missing, incomplete or unreliable data in the process of supplier qualification.

Missing values indicate that a situation involves uncertainty. There are a number of methods from statistics and data envelopment analysis for handling missing and/or imprecise data, such as:

- listwise deletion,

- pairwise deletion,

- mean substitution,

- regression imputation, and

- hot-deck imputation.

(Roth-Switzer 1995).

Two types of DEA models are recommended for use with imprecise data:

- fuzzy DEA (Kao and Liu 2000), and

- interval DEA (Smirlis et al. 2006).

Due to the lack of sufficient historical data, probability estimates are not meaningful enough. The fuzzy DEA model applies fuzzy set theory to develop a methodology for solving the problems with missing data that are encountered in measuring relative efficiencies within the DEA framework (Kao and Liu 2000). In fuzzy set theory, uncertainty is assessed by means of possibility, involving the use of possibility distributions to describe the level of possibility. Unlike probability, possibility involves subjective cognition.

Missing input and output values cannot be handled using the original data envelopment analysis (DEA) models. Smirlis et al. (2006) introduce an approach based on interval DEA that allows the evaluation of units with missing values along with the other units using crisp data. Missing values are replaced by intervals to which the unknown values are likely to belong. The proposed models are able to identify an upper and a lower bound for the efficiency scores of units with missing values. The efficiency analysis is further extended by estimating new values for the initial interval bounds that may turn the unit into an efficient one.

This paper proposes a third model for handling missing or imprecise data: the parametrization of missing or imprecise data.

After the introduction, the second part of this article examines the relevancy of supplier pre- and post-qualification. It presents a review of the literature to explain the findings of research related to extended purchasing process and supplier evaluation methodologies. The data which is available for pre- and post-qualification is not always accurate, and does not allow the purchaser to inform the supplier about the areas in which it should develop (to better meet the purchaser's needs). This also calls attention to the importance of identifying the critical value(s) above which a supplier may be considered effective, which are of relevance in improving the status of the latter from potential 
suppliers to qualified suppliers. Part 3 discusses the decision problem presented in the previous sections from the perspective of DEA. This involves mathematically transforming the problem into a parametric linear programming problem that can be solved using a parameterized DEA method. Since the changed parameters appear in the technological coefficient matrix of the parametric linear programming model, the problem cannot be solved analytically. Our solution is to use a simulation method. The final section summarizes our results.

\section{Literature review}

Supplier evaluation is one of the most widely researched areas of purchasing management. As it is beyond the aim and scope of this paper to provide a detailed review of the literature, we mainly limit the discussion to some important findings that support the reasoning behind the development of our method.

\section{Supplier evaluation criteria and methods}

Important streams of purchasing management literature focus on identifying evaluation criteria and developing methodology that supports decision making.

Papers that investigate evaluation criteria tend to present lists of the most relevant measures (Dickson, 1966, Weber et al., 1991). Quality, price, delivery, and services are often highlighted as important elements of supplier evaluation (Bruno et al. 2016, Dey et al. 2015). Other literature reviews differentiate traditional management and environmental criteria (Rezaei et al. 2016, Govindan et al. 2015, Deshmukh and Vasudevan 2014). This approach reflects the fact that while the former evaluation criteria are used to appraise business-related features, the latter represent broader social and environmental values.

A large number of methodologies have been developed to compare these criteria. Literature reviews (e.g. Ho et al. 2010, Agarwal et al. 2011) show how a broad set of multi-criteria decisionmaking approaches have been used in scientific publications. Most of these consider supplier evaluation an optimisation problem, and attempt to demonstrate the appropriateness of the posited models for a specific situation. As literature reviews reflect, the use of the related terms in papers is far from uniform: many of them broadly clarify the purpose of the models they compare (e.g. Ho et al. 2010, Govindan et al. 2015), but fail to make a distinction between the understandings of terms and types of purchasing situations.

\section{Supplier evaluation in the purchasing process}

Purchasing process models are one of the focal areas of purchasing and supply management literature, in which supplier evaluation is awarded an important role. These process models are a schematic representation of the main tasks, activities and processes that constitute purchasing and supply management. They may describe purchasing as a linear or a cyclical process, or emphasize that purchasing is a decision-making process (Chen et al. 2017). As a result, these process models 
formulate tasks with different priorities and different perspectives. Supplier selection is the central element of each of them.

Nevertheless, supplier selection as a part of the purchasing process is subject to different interpretations. Some authors define the activity as making a decision about the best supplier (e.g. Boran et al. 2009, Chai et al. 2013), while other authors consider it a multistage process. In this multistage form of evaluation, selection may be extended with pre-qualification (de Boer et al. 2001, Dobler and Burt 1995) while other authors also highlight the role of ex-post evaluation (van Weele 2000, Monczka et al. 2002, Igarashi et al. 2013). This also places the emphasis on strategic tasks, as with post-evaluation the purchasing process becomes a closed cycle (van Raaij 2016, Johnsen et al. 2014), connecting tactical-level activities with strategic ones through supplier segmentation (Wetzstein et al. 2016). At this advanced stage, the process goes beyond the traditional activity of purchasing management. Data acquired using such an extended system of evaluation may form the basis of supplier management and supplier development (Glock et al. 2017).

\section{Elements of the purchasing process}

Based on the findings of literature, three main elements can be identified as part of supplier evaluation. They are different in terms of their goals and they have different expectations about the methods in terms of their output. The differences can be formulated as follows:

Pre-qualification or pre-selection: this is an evaluation element which precedes the stage of supplier selection and contracting. The aim of this phase is to reduce a larger number of potential suppliers to a smaller set of acceptable suppliers by eliminating inefficient ones (Sen et al. 2010, Lasch, Janker 2005), or those who are not able to provide evidence of suitable capabilities (Wan, Beil 2009). The concept of prequalification may also be to provide information to potential suppliers about their capabilities in the form of benchmarking, indicating how their performance level should be improved. Results may also be used in negotiations with suppliers (Weber and Desai 1996).

Stemming from the goal of shortlisting suppliers, the process can be considered one of sorting (Manshadi et al., 2015). The literature (e.g. Sen et al. 2010, Sarkar and Mohapatra 2006, Yu et al. 2014) identifies several relevant methods for doing this. When new suppliers enter the evaluation process, another methodological challenge arises: data availability can be a problem, as before the bidding process only public data may be available, or it may be costly to check data accuracy and validity (Wan and Beil 2009).

Supplier selection or choice of supplier: this is the process of defining the best supplier from a set of supplier offers, and involves ranking acceptable suppliers. The task is frequently addressed in the literature. Several methods have been proposed (e.g. linear weight models, TCO models, mathematical programming models, statistical models, and artificial intelligence models (de Boer et al. 2001).

Post-qualification or post-evaluation: this involves evaluating the performance of suppliers after delivery. The purpose of such evaluations may be to check whether suppliers have met expectations 
so as to support the next round of supplier selection (Roodhooft and Konings 1997). This phase may also involve the periodic control of the performance of active suppliers (Luzzini et al. 2014), and can serve supplier management purposes as well: the aim may be to identify those elements of supplier performance and capabilities which can be improved (Zhu et al. 2010). This last step may result in supplier segmentation, according to which suppliers may be further classified to facilitate the application of different strategies to different segments (Rezaei and Ortt 2012).

Post-qualification or post-evaluation means the process of sorting suppliers according to their performance. The focus here is on the data that is available about existing suppliers based on their past performance.

As this brief overview has revealed, new elements of the evaluation process (pre- and postqualification) represent different kinds of tasks from a methodological point of view. The goal here is to qualify and screen suppliers, thus purchasers do not seek to rank them, but to establish and verify compliance. The literature about the potential difficulties involved in these new elements of evaluation is scarce (Yund et al. 2012).

After reviewing the literature, Wand and Beil (2009) claim that qualification is a costly process due to data requirements relating to verifying the capability of suppliers to perform adequately. Obtaining, checking and monitoring these data is expensive. Missing data, according to Jin et al. (2014), are also a problem. However, supplier development is a vital part of supplier management, and both functions are supposed to rely on the evaluation of supplier competencies and performance. This calls attention to the importance of identifying methods for handling evaluations in the presence of incomplete data.

\section{A DEA Framework for green supplier selection}

Because of its ease of use, the DEA method is of practical importance in supplier evaluation, making an investigation of its applicability relevant. One of the most important limitations of this method is that the weights for various supplier performance attributes that are used in the weighted, additive scoring methods are arbitrarily defined (Narasimhan et al. 2001). Thus, the final ranking of a supplier is significantly dependent on the assignment of those weights, which are often difficult to specify in an objective manner. In this section, with the help of DEA, we develop a framework to assist with the evaluation of suppliers in a way that allows for control of the result of the qualification process. Our goal is to identify the specific level of a criterion which affects the results of the qualification process, thereby supporting supplier development. In the linear programming literature, this is referred to as a sensitivity analysis.

A supplier evaluation method may be formulated as a decision making problem. Let us assume that suppliers are evaluated along management and green criteria. Management criteria are the usual supplier evaluation criteria (such as price, lead time, and quality of products, etc.). Green criteria are listed in the last section of this paper. We assume that the green criteria are the outputs of the examined method, and managerial criteria are the inputs (independent variables). In this context, we can examine the sustainable performance of a supplier according to classical managerial performance. 


\subsection{The application of the green DEA model in supplier selection}

Let us assume that the purchaser seeks to evaluate $p+1$ suppliers. The number of traditional management criteria is $n$ and the number of green criteria is $m$. The evaluation of supplier $i$ is defined using vectors $\left(\mathbf{x}_{i}, \mathbf{y}_{i}\right)$, where vector $\mathbf{x}_{i}$ is the value of the management criteria and vector $\mathbf{y}_{i}$ is the green criteria. This partitioning of evaluation criteria has been promoted by Dobos and Vörösmarty (2014), and this paper follows this method.

Method DEA is a general framework for evaluating suppliers in materials and supply management in the absence of weights for criteria. The application of the DEA method is based on the categories "inputs", "outputs", and efficiencies. The basic method was constructed by Charnes et al. (1978) to determine the efficiency of decision making units (DMU). The model the authors propose is a hyperbolic programming model under linear conditions. One method for generally solving such kinds of models was first investigated by Martos (1964) who examined the problem as a special case of linear programming models. The aim of the DEA model is to construct weights for management (input) and green (output) criteria, which are defined as the vectors $\mathbf{v}$ and $\mathbf{u}$, respectively.

Let us formulate the DEA model in the following way, assuming that we are examining the efficiency of the $0^{\text {th }}$ decision-making unit:

$$
\mathbf{u} \cdot \mathbf{y}_{0} \rightarrow \max
$$

s.t.

$$
\begin{aligned}
& \mathbf{u} \cdot \mathbf{y}_{j} / \mathbf{v} \cdot \mathbf{x}_{j} \leq 1 ; j=0,1,2, \ldots, p . \\
& \mathbf{u} \geq \mathbf{0}, \mathbf{v} \geq \mathbf{0} .
\end{aligned}
$$

Model (1)-(3) is the basic DEA method model, which can be reformulated as a linear programming model in the following form:

$$
\mathbf{u} \cdot \mathbf{y}_{0} \rightarrow \max
$$

s.t.

$$
\begin{aligned}
& \mathbf{v} \cdot \mathbf{x}_{0}=1, \\
& \mathbf{u} \cdot \mathbf{y}_{j}-\mathbf{v} \cdot \mathbf{x}_{j} \leq 0 ; j=0,1,2, \ldots, p . \\
& \mathbf{u} \geq \mathbf{0}, \mathbf{v} \geq \mathbf{0} .
\end{aligned}
$$

Models (4)-(7) may be solved using commercial software. Throughout the paper, we apply similar software to construct our numerical examples.

\subsection{Extension of the green DEA model using parametrization}


Let us examine the $i$ th green criterion. The question now is how to improve the green criterion for $0^{\text {th }}$ DMU in order to improve efficiency. The new model has the following form:

$\mathrm{E}_{0}(t)=\mathbf{u} \cdot\left(\mathbf{y}_{0}+t \cdot \mathbf{e}_{i}\right) \rightarrow \max$

s.t.

$\mathbf{v} \cdot \mathbf{x}_{0}=\mathbf{1}$,

$\mathbf{u} \cdot\left(\mathbf{y}_{0}+t \cdot \mathbf{e}_{i}\right)-\mathbf{v} \cdot \mathbf{x}_{0} \leq \mathbf{0}$,

$\mathbf{u} \cdot \mathbf{y}_{j}-\mathbf{v} \cdot \mathbf{x}_{j} \leq \mathbf{0} ; j=1,2, \ldots, p$.

$\mathbf{u} \geq \mathbf{0}, \mathbf{v} \geq \mathbf{0}$.

In this last model, vector $\mathbf{e}_{i}$ is a unit vector. Function $\mathrm{E}_{0}(t)$ measures the change in efficiency of $0^{\text {th }}$ DMU which is dependent on the value of the criterion as a function of parameter $t$. The problem $\left(4^{\prime}\right)-\left(7^{\prime}\right)$ is a parametric linear programming problem. In parametric linear programming there are three types of parametrization:

- parametrization of the right-hand-side (RHS),

- parametrization of the cost function, and

- parametrization of technological coefficients.

Model (4')-(7') belongs to third type of problem because it involves parametrized technological coefficients.

For the first two parametric problems there are very good solutions in the literature (See Dantzig and Thapa 2003). The third problem is harder to solve: there are no good, standardized results with which to characterize optimal solutions according to changes in technological parameters. Some related results are summarized in Gal (1979).

Because there are no standardized results applicable to parametric linear programming, we have chosen some numerical examples to construct optimal weights for the DEA models.

\subsection{Using the parametrized green supplier selection model: a numerical example}

We now provide an example of the numerical analysis. Let us assume that a firm has information about the management criteria of its suppliers, such as lead time, quality of products, and price. The relevant green criteria in our analysis are the level of reusability of the offered products and the level of $\mathrm{CO} 2$ emissions associated with the production process.

The basic data for the example are represented in Table 1. The example meets the general rule for the minimum number of decision making units (suppliers) to ensure accurate results. The number of suppliers is equal to 18 ; i.e., $p=\max \{m \cdot n ; 3 \cdot(m+n)\}$, where $p$ is the number of suppliers and the numbers $m$ and $n$ are the number of outputs and inputs (Cooper et al. 2001). There are usually a large number of suppliers involved in pre- and post-qualification. The goal is to sort and certify suppliers and to analyze and improve their performance. 
Insert Table 1. here.

Let us transform the data in Table 1 so that better results for a criterion will result in numerically higher scores. The transformation of the basic data is based on a utility function. The utility function of the criteria ranges between 1 and 20. For the inputs (i.e. the managerial data) we chose the following function:

$U_{i j}=\frac{19}{x_{j}^{\max }-x_{j}^{\min }} \cdot x_{i j}-19 \cdot \frac{x_{j}^{\max }}{x_{j}^{\max }-x_{j}^{\min }}-1$,

where value $x_{j}^{\max }$ is the most preferable value for criterion $j$, and value $x_{j}^{\min }$ is the worst value for this criterion. For the green (i.e., output) data we construct:

$U_{i j}=\frac{19}{x_{j}^{\max }-x_{j}^{\min }} \cdot x_{i j}-19 \cdot \frac{x_{j}^{\max }}{x_{j}^{\max }-x_{j}^{\min }}+20$,

where value $x_{j}^{\max }$ is the most preferable value for criterion $j$, and value $x_{j}^{\text {min }}$ is the worst value for this criterion. The transformation is an affine one, as analysed and described by Färe and Grosskopf (2013).

The new, transformed table looks like this:

Insert Table 2. here.

Optimal efficiency measures for suppliers are represented in Table 3 and are dependent on changes in the criterion for $\mathrm{CO} 2$ emissions.

Insert Table 3. here.

In the numerical example, two sets of criteria were formulated: management (traditional purchasing criteria) and green criteria. The results can be interpreted practically, as the $5^{\text {th }}$ and $16^{\text {th }}$ suppliers are the most efficient DMU's in a sustainability context. Identifying which supplier to choose is the next problem in the selection process. Other criteria could be involved in the decision-making process (e.g. logistical performance). Supplier $0^{\text {th }}$ must reduce their $\mathrm{CO} 2$ emissions from $30 \mathrm{~g}$ to $10 \mathrm{~g}$ to improve their status, but this will not be efficient. The result shows that these suppliers are Pareto optimal in the context of decision theory.

The weights vector suggests that the weight of lead time and price should be neglected in the evaluation of suppliers. The reusability component receives more weight than other criteria. In this evaluation situation, the reverse logistic subsystem of the vendor should be weighted highly so as to influence the selection decision. 


\section{Conclusions}

Although the use of DEA for evaluating suppliers is widespread, it is rarely used for pre- and postqualification/selection. These two processes call for the incorporation of important data, helping qualify a potential supplier for inclusion in the supply pool. Our article focuses on a specific situation; how to deal with missing data, or imprecise data management. The importance of the pre- and post-qualification phases is increasing as these phases are used to provide input for supplier management activities, including supplier development, making purchasing more of a strategic task.

During pre- and post-qualification, numerous suppliers may and should be evaluated, unlike during supplier selection. Accordingly, the use of DEA is more appropriate for dealing with these two phases.

Parameterizing the classical DEA method makes it possible for purchasers to inform suppliers about the improvements they need to make to be considered for registration as qualified suppliers. Since the problem is not mathematically manageable, the simulation method appears to be appropriate for solving such problems. However, with parameter changes we need to solve an increasing number of linear programming problems.

One opportunity for further research is suggested: in the present model we changed only one element of the technology matrix and considered it a function of the change in the efficiency indicator. It would be worth examining whether to change (and to what extent) if more than one element should be parameterized for the technology matrix; i.e. the evaluation vectors of suppliers.

This project was supported by NKFIH K124644

\section{References:}

- Agarwal P, Sahai M, Mishra V, Bag M, Singh V (2011) A review of multi-criteria decision making techniques for supplier evaluation and selection. Int $\mathbf{J}$ of Ind Eng Computations 2(4): 801-810.

- Bharadwaj N (2004) Investigating the decision criteria used in electronic components procurement. Ind Mark Manag 33(4): 317-323.

- Boran FE, Genç S, Kurt M, Akay D (2009) A multi-criteria intuitionistic fuzzy group decision making for supplier selection with TOPSIS method. Expert Syst with Appl 36(8): 11363-11368.

- Bruno G, Esposito E, Genovese A, Passaro R (2012) AHP-based approaches for supplier evaluation: Problems and perspectives. J of Purch and Suppl Manag 18(3): 159-172.

- Bruno G, Esposito E, Genovese A, Simpson M (2016) Applying supplier selection methodologies in a multi-stakeholder environment: A case study and a critical assessment. Expert Syst with Appls 43: 271-285. 
- Chai J, Liu JN, Ngai EW (2013) Application of decision-making techniques in supplier selection: A systematic review of literature. Expert Syst with Appls 40(10): 3872-3885.

- Charnes V, Cooper WW, Rhodes E (1978) Measuring the efficiency of decision making units, Eur J of Oper Res 2: 429-444.

- Chen C, Suurmond R, van Raaij E, Bäckstrand J (2017) Purchasing process models: Tools for teaching Purchasing and Supply Management, Proceedings of the 24. IPSERA Conference WP. 132: 1-12.

- Dantzig GB, Thapa MN (2003) Linear Programming 2: Theory and Extensions, Springer, New York et al.

- de Boer L, Labro E, Morlacchi P (2001) A review of methods supporting supplier selection. Europ J of Purch and Suppl Manag 7(2): 75-89.

- Deshmukh AJ, Vasudevan H (2014) Emerging supplier selection criterion in the context of traditional vs green supply chain management, Int. J of Manag Value and Suppl Chains 5(1): 19-33

- Dey PK, Bhattacharya A, Ho W, Clegg B (2015) Strategic supplier performance evaluation: A case-based action research of a UK manufacturing organisation. Int J of Prod Econ 166: 192-214.

- Dickson GW (1966) An analysis of vendor selection systems and decisions, J of Purch 2 (1): 5-17.

- Dobler D, Burt DN (1995) Purchasing and Supply Management: Text and Cases, $6^{\text {th }}$ edition, MGraw-Hill

- Dobos I, Vörösmarty G (2014) Green supplier selection and evaluation using DEA-type composite indicators. Int J of Prod Econ 157(1): 273-278.

- Gal T (1979) Postoptimal analyses, parametric programming, and related topics. McGraw Hill Co New York

- Glock CH, Grosse EH, Ries JM (2017) Decision support models for supplier development: systematic literature review and research agenda. Int J of Prod Econ 193: 798-812.

- Govindan K, Rajendran S, Sarkis J, Murugesan P (2015) Multi criteria decision making approaches for green supplier evaluation and selection: a literature review. J of Clean Prod 98: 66-83.

- Ho W, Xu X, Dey PK (2010) Multi-criteria decision making approaches for supplier evaluation and selection: A literature review. Eur J of Oper Res 202(1): 16-24.

- Hult, GTM, Hurley, RF, Giunipero LC, Nichols, EL (2000) Organizational learning in global purchasing: a model and test of internal users and corporate buyers. Decis Sci 312: 293-325.

- Igarashi M, de Boer L, Fet, AM (2013) What is required for greener supplier selection? A literature review and conceptual model development. J of Purch and Suppl Manag 19(4): 247-263.

- Jin Y, Ryan JK, Yund W (2014) Sourcing decisions with competitive suppliers and imperfect information. Decis Sci 45(2): 229-254. 
- Johnsen T, Howard M, Miemczyk J (2014) Purchasing and supply chain management: A sustainability perspective. Routledge

- Kao C, Liu ST (2000) Data envelopment analysis with missing data: an application to university libraries in Taiwan. J of the Oper Res Soc 51: 897-905.

- Kaufmann L, Carter RC, Buhrmann C (2010) Debiasing the supplier selection decision: a taxonomy and conceptualization, Int J of Phys Distrib Logist Manag 40(10): 792-821.

- Lasch R, Janker C G (2005) Supplier selection and controlling using multivariate analysis. Int. J. of Physical Distr \& Logist Man. 35(6): 409-425.

- Luzzini, D, Caniato, F, Spina G (2014) Designing vendor evaluation systems: An empirical analysis. J of Purch and Suppl Manag 20(2): 113-129.

- Manshadi E D, Mehregan M R, Safari H (2015) Supplier Classification Using UTADIS Method Based on Performance Criteria. International Journal of Academic Research in Business and Social Sciences, 5(2): 31-45.

- Martos B (1964) Hyperbolic programming, Naval Res Logist Q 11(2): 135-155.

- Monczka RM, Handfield R, Guinipero LC, Patterson, JL, Walters, D (2009) Purchasing and Supply Chain Management, South-Western Cengage Learning

- Narasimhan R, Talluri S, Mendez D (2001) Supplier evaluation and rationalization via data envelopment analysis: an empirical examination. J of supply chain manag., 37(2), 28-37.

- Rezaei J, Nispeling T, Sarkis J, Tavasszy L (2016) A supplier selection life cycle approach integrating traditional and environmental criteria using the best worst method. J of Clean Prod, 135, 577-588.

- Rezaei J, Ortt R (2012) A multi-variable approach to supplier segmentation. Int J of Prod Res 50(16): 4593-4611.

- Roodhooft F, Konings J (1997) Vendor selection and evaluation an activity based costing approach. European J of Oper Res 96(1): 97-102.

- Roth PL, Switzer FS (1995) A Monte Carlo analysis of missing data techniques in a HRM setting. J of Manag., 21(5): 1003-1023.

- Ryan JK, Yund W, Jin Y (2011) Design and Analysis of Two Stage Procurement Processes. In IIE Annual Conference. Proceedings January (p. 1). Institute of Ind and Syst Engineers (IISE)

- Sarkar A, Mohapatra PK (2006) Evaluation of supplier capability and performance: A method for supply base reduction. J of Purch and Suppl Manag 12(3): 148-163.

- Şen, CG, Şen S, Başlıgil H (2010) Pre-selection of suppliers through an integrated fuzzy analytic hierarchy process and max-min methodology. Int J of Prod Res 48(6): 1603-1625

- Smirlis YG, Maragos EK, Despotis DK (2006) Data envelopment analysis with missing values: An interval DEA approach. Applied Math and Comp 177(1): 1-10.

- van Raaij E (2016) Purchasing Value: Purchasing and Supply Management's Contribution to Health Service Performance, Inaugural Addresses Resh in Manag Series

- van Weele A (2009): Purchasing and Supply Chain Management, 5th edition Cengage

- Wan Z, Beil DR (2009) RFQ auctions with supplier qualification screening. Oper Res 57(4): 934-949.

- Weber CA, Current JR, Benton WC (1991) Vendor selection criteria and methods. European J of Oper Res 50(1): 2-18. 
- Weber CA, Desai A (1996) Determination of paths to vendor market efficiency using parallel coordinates representation: a negotiation tool for buyers. E J of Oper Res 90(1): 142-155.

- Wetzstein A, Hartmann E, Benton Jr WC, Hohenstein, NO (2016) A systematic assessment of supplier selection literature-State-of-the-art and future scope. Int J of Prod Econ 182: 304-323.

- Yu, C, Wong TN (2014) A supplier pre-selection model for multiple products with synergy effect. Int J of Prod Res 52(17): 5206-5222.

- Yund W, Ryan JK, Jin Y (2012, January) Design of Two-Stage Procurement Processes with Imperfect Information on Supplier Capabilities. In IIE Annual Conference. Proceedings (p. 1). Institute of Ind and Syst Engineers (IISE).

- Zhu Q, Dou Y, Sarkis J (2010) A portfolio-based analysis for green supplier management using the analytical network process. Suppl Chain Manag: An Int J 15(4): 306-319 